\title{
Evolução espaço-temporal do uso da terra da microbacia do Córrego Descalvado - Botucatu, SP
}

\author{
Sérgio Campos ${ }^{1}$ \\ Ana Paula Barbosa ${ }^{1}$ \\ Muriel Cicatti Emanoeli Soares ${ }^{1}$ \\ Raquel Cavasini ${ }^{1}$ \\ Marina Granato ${ }^{1}$ \\ Mariana Garcia da Silva ${ }^{1}$ \\ Débora Marques Araújo ${ }^{1}$ \\ Milena Montanholi Mileski ${ }^{1}$ \\ ${ }^{1}$ Faculdade de Ciências Agronômicas/UNESP \\ Rua José Barbosa de Barros, 1780 \\ 18610 - 307 - Botucatu - SP, Brasil \\ seca@fca.unesp.br
}

\begin{abstract}
Resumo: O trabalho visou obter a evolução do uso da terra da microbacia do Ribeirão Descalvado - Botucatu (SP), obtido em fotografias aéreas e imagem de satélite. As bases cartográficas foram: a carta planialtimétrica (IBGE, 1969), as fotografias aéreas de 1962 e a imagem de satélite de 2006, bem como foram utilizados os Softwares IDRISI Andes 15.0 e CARTALINX. O uso da terra mostrou que as pastagens ocuparam a maior parte da área $(53 \%)$. As pastagens $(53,74 \%)$ e as capoeiras $(21,94 \%)$ representaram mais de $3 / 4$ da área $(75,68 \%)$, mostrando com isso a predominância de solos de baixa fertilidade. A área vem sendo ambientalmente conservada, pois não apresenta deficiência de florestamento, visto que se apresenta coberta com mais de $20 \%$ de matas, mínimo exigido pelo Código Florestal Brasileiro vigente (20\%).O alto índice de ocupação do solo por pastagem (53,74\%), é reflexo da predominância da pecuária regional.
\end{abstract}

Palavras Chaves: microbacia, sensoriamento remoto e Software CARTALINX.

Abstract: The work sought to obtain the evolution of the soil use of Stream Descalvado watershed - Botucatu (SP), obtained in aerial photographs and satellite image. The cartographic bases were: the shart planialtimetric (IBGE, 1969), the aerial photographs of 1962 and the satellite of 2006, as well as the Softwares IDRISI Andes 15.0 and CARTALINX were used. The soil use showed that the pastures occupied most of the area $(53 \%)$. The pastures $(53,74 \%)$ and the brushwoods $(21,94 \%)$ they acted more than $3 / 4$ of the area $(75,68 \%)$, showing with that the predominance of soils of low fertility. The area is being conserved environmentaly, therefore it doesn't present foresty deficiency, because he/she comes covered with more than $20 \%$ of forests, minimum demanded by the Brazilian Forest Code effective (20\%). The high index of occupation of the soil for pasture $(53,74 \%)$, it is reflex of the predominance of the regional livestock.

Key words: watershed, remote sensing and Software CARTALINX.

\section{Introdução}

O sensoriamento remoto é a ciência e a arte de se obterem informações sobre um objeto, área ou fenômeno, através da análise de dados coletados por aparelhos denominados sensores, que não entram em contato direto com os alvos em estudo (Crepani, citado por Vettorazzi, 1992).

Dentre os sistemas de sensoriamento remoto disponíveis, as fotografias aéreas e as imagens de satélites são as ferramentas mais utilizadas em trabalhos de exploração e monitoramento ambiental.

A análise do uso e cobertura do solo (Rodrigues, 2000) obtidas através de informações obtidas pelo sensoriamento remoto, é de grande utilidade ao planejamento e administração da ocupação ordenada e racional do meio físico, além de possibilitar avaliar e monitorar a preservação de áreas de vegetação natural. Segundo a autora, o sensoriamento remoto é uma 
ferramenta de grande valia para auxiliar o homem na caracterização do meio físico, biótico e de áreas submetidas ao processo de antropismo.

A bacia hidrográfica (Morais, 1997) no planejamento da ocupação é uma necessidade numa sociedade com usos crescentes da água, a qual tende a ocupar espaços com riscos de inundação, além de danificar o seu meio. A tendência atual envolve desenvolvimento sustentado de bacia hidrográfica, que implica no aproveitamento racional dos recursos, com o mínimo dano ao ambiente.

O levantamento de sua degradação é imprescindível para o conhecimento da realidade e a busca de sua recuperação.

Este trabalho teve como objetivo caracterizar, quantificar e mapear as áreas da microbacia do Ribeirão Descalvado - Botucatu (SP), onde a evolução do uso da terra foi discriminada por fotografias aéreas pancromáticas e imagens de satélite.

\section{Material e Métodos}

O presente trabalho está sendo desenvolvido na microbacia do Ribeirão Descalvado, situada na porção norte do município de Botucatu (SP). Sua situação geográfica é definida pelas coordenadas: latitude $22^{\circ} 50^{\prime} 05^{\prime \prime}$ a $22^{\circ} 54^{\prime} 26^{\prime \prime}$ S e longitudes $48^{\circ} 26^{\prime} 36^{\prime \prime}$ a $48^{\circ} 22^{\prime} 29^{\prime \prime} \mathrm{W} \mathrm{Gr}$, com uma área de 2051,13 ha.

Os pontos de controle no processo de digitalização do mapa de ocupação do solo foram obtidos da Carta Planialtimétrica editada pelo Instituto Brasileiro de Geografia e Estatística IBGE em 1969, folha de Botucatu (SF-22-R-IV-3), escala 1:50.000.

As áreas das coberturas vegetais, a área útil e a linha de vôo foram obtidas através de fotografias aéreas pancromáticas provenientes das coberturas aerofotogramétricas do Estado de São Paulo, de 1962, com escala nominal aproximada de 1:25000 e com recobrimento longitudinal de aproximadamente $60 \%$ e $30 \%$ na lateral.

O processamento dos dados foi realizado num microcomputador Pentium, $200 \mathrm{~Hz}, \mathrm{HD} 2,1$ Gb, $64 \mathrm{Mb}$ de memória RAM, com saída para impressora a jato de tinta HP Deskjet 692 C. Para entrada das informações analógicas como limite da microbacia e áreas de cobertura vegetal foi utilizado o Scanner Genius Vivid Pro II.

O contorno da área da microbacia do Ribeirão Descalvado - Botucatu (SP) foi realizado manualmente na Carta Planialtimétrica editada pelo Instituto Brasileiro de Geografia e Estatística - IBGE em 1969, folha de Botucatu (SF-22-R-IV-3), escala 1:50000, segundo os pontos mais elevados em torno da drenagem, tendo-se como base a definição de Rocha (1991) para bacia hidrográfica.

Para obtenção do mapa das coberturas vegetais de 1962 foi feita, inicialmente, uma montagem de todo o conjunto de fotografias aéreas pancromáticas correspondentes à área da microbacia do Ribeirão Descalvado, sendo em seguida traçadas linhas de vôo e a delimitação da área efetiva, conforme Coelho (1972); depois, com o auxílio da estereoscopia foram decalcadas, em filme de poliéster Terkron D-50 mícrons, as áreas das coberturas vegetais, objeto de estudo.

O mapa das coberturas vegetais obtido em filme poliéster TerKron D-50 mícrons foi scanerizado para transformação da imagem raster para vector. Em seguida o arquivo vetorial foi importado para o IDRISI, em formato TIFF e georreferenciado.

A interpretação das classes de uso e cobertura do solo de 2006 foi feita com base na imagem de satélite digital, bandas 3, 4 e 5 do Sensor TM, do LANDSAT 5, da órbita 220, ponto 76, quadrante A, passagem de 23/10/2006, através da classificação supervisionada.

As imagens de satélite de 2006 foram georreferenciadas no IDRISI Andes 15.0, onde foram feitas as composições RGB para cada uma das datas. Tais composições foram convertidas para o formato BMP através do CartaLinx, onde foram interpretadas, os polígonos vetorizados foram 
exportados para o ArcView 3.2 para a elaboração do mapa final, sendo as áreas quantificadas através do comando “Área” do menu "Database Query” pertencente ao módulo “Analysis".

\section{Resultados e Discussão}

A cobertura vegetal sofreu e vem sofrendo constantes modificações ao longo dos anos com a ação do ser humano, sendo mais intensa essa dinâmica nos solos com melhor fertilidade e de condições ecológicas mais propícias para a exploração agropecuária.

Os solos mais pobres em função do aumento da densidade demográfica e do aperfeiçoamento das técnicas agronômicas vêm também sendo utilizados (Borgonovi \& Chiarini, 1965). Assim, na região de Botucatu, as áreas de matas com clima e topografia favoráveis, apresentam apenas vestígios da cobertura vegetal original, ao passo que os cerrados vêm diminuindo progressivamente pela utilização de suas áreas, principalmente com culturas de alto retorno econômico, como é o caso da cultura da cana-de-açúcar.

A análise do uso da terra na microbacia do Ribeirão Descalvado - Botucatu (SP) mostra que as pastagens, as capoeiras e os reflorestamentos foram as coberturas vegetais que ocuparam maior parte da área, representando mais de $85 \%(85,96 \%)$.

As pastagens com um aumento de $125,98 \%$ e as capoeiras (Figuras 1 e 2 e Tabela1) vem representando mais de $75 \%$ da área da microbacia $(75,68 \%$ ), ou seja, cobrem 1686,6ha, mostrando com isso a predominância de solos de baixa fertilidade (Campos, 1993).

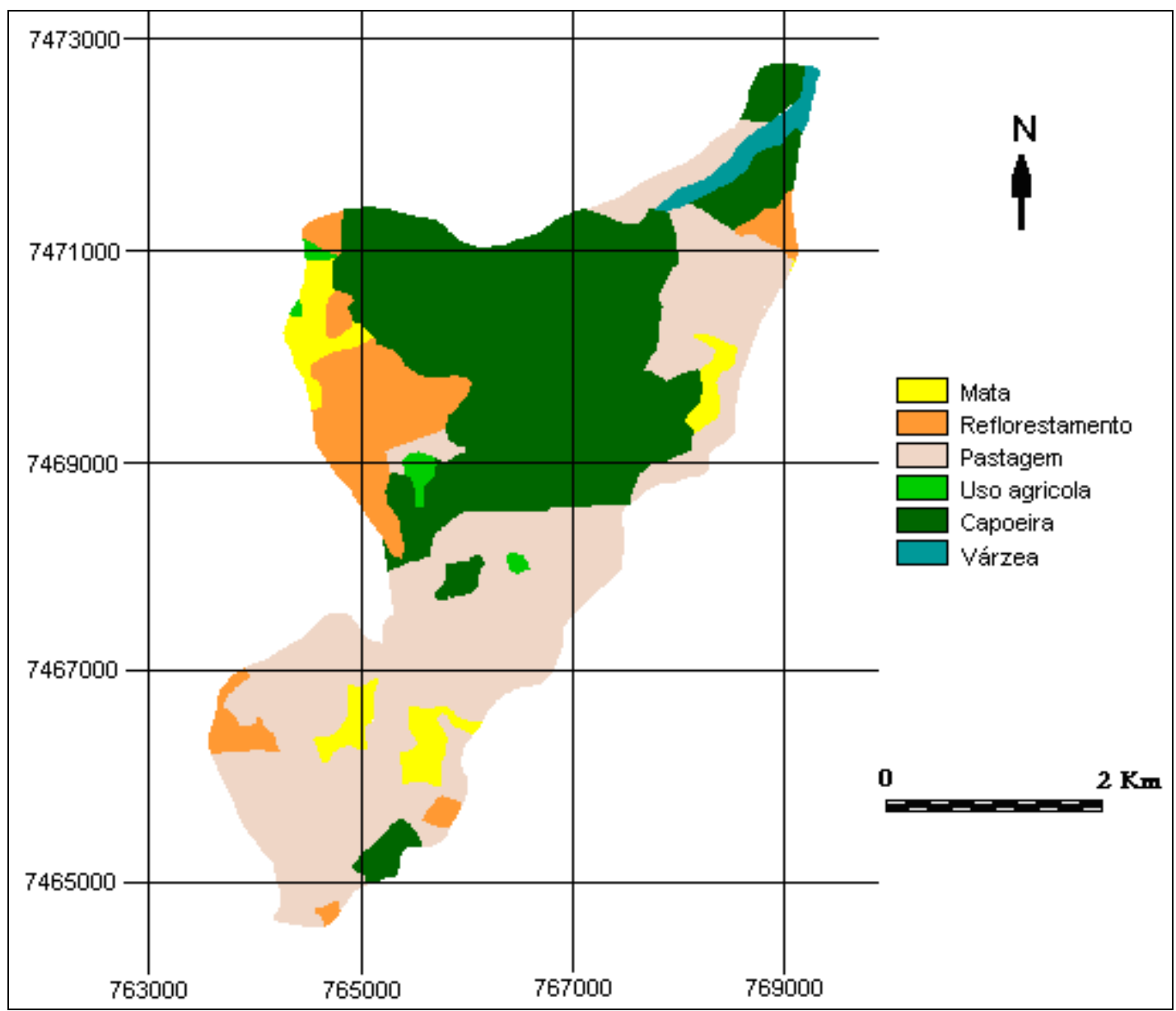

Figura 1. Ocupação do solo da microbacia do Ribeirão Descalvado - Botucatu, SP, obtida em fotografias aéreas de 1962 
Tabela 1. Uso da terra na microbacia do Ribeirão Descalvado - Botucatu, SP

\begin{tabular}{|c|c|c|c|c|}
\hline \multirow{2}{*}{ Ocupação do solo } & \multicolumn{2}{|c|}{1962} & \multicolumn{2}{|c|}{2006} \\
\hline & ha & $\%$ & ha & $\%$ \\
\hline Mata & 106,73 & 5,20 & 175,84 & 8,57 \\
\hline Reflorestamento & 210,40 & 10,25 & 210,80 & 10,28 \\
\hline Uso Agrícola & 16,32 & 0,80 & 76,66 & 3,73 \\
\hline Pastagens & 874,99 & 42,66 & 1102,22 & 53,74 \\
\hline Capoeira & 807,84 & 39,39 & 449,97 & 21,94 \\
\hline Várzea & 34,85 & 1,70 & 35,64 & 1,74 \\
\hline TOTAL & 2051,13 & & 2051,13 & 100 \\
\hline
\end{tabular}

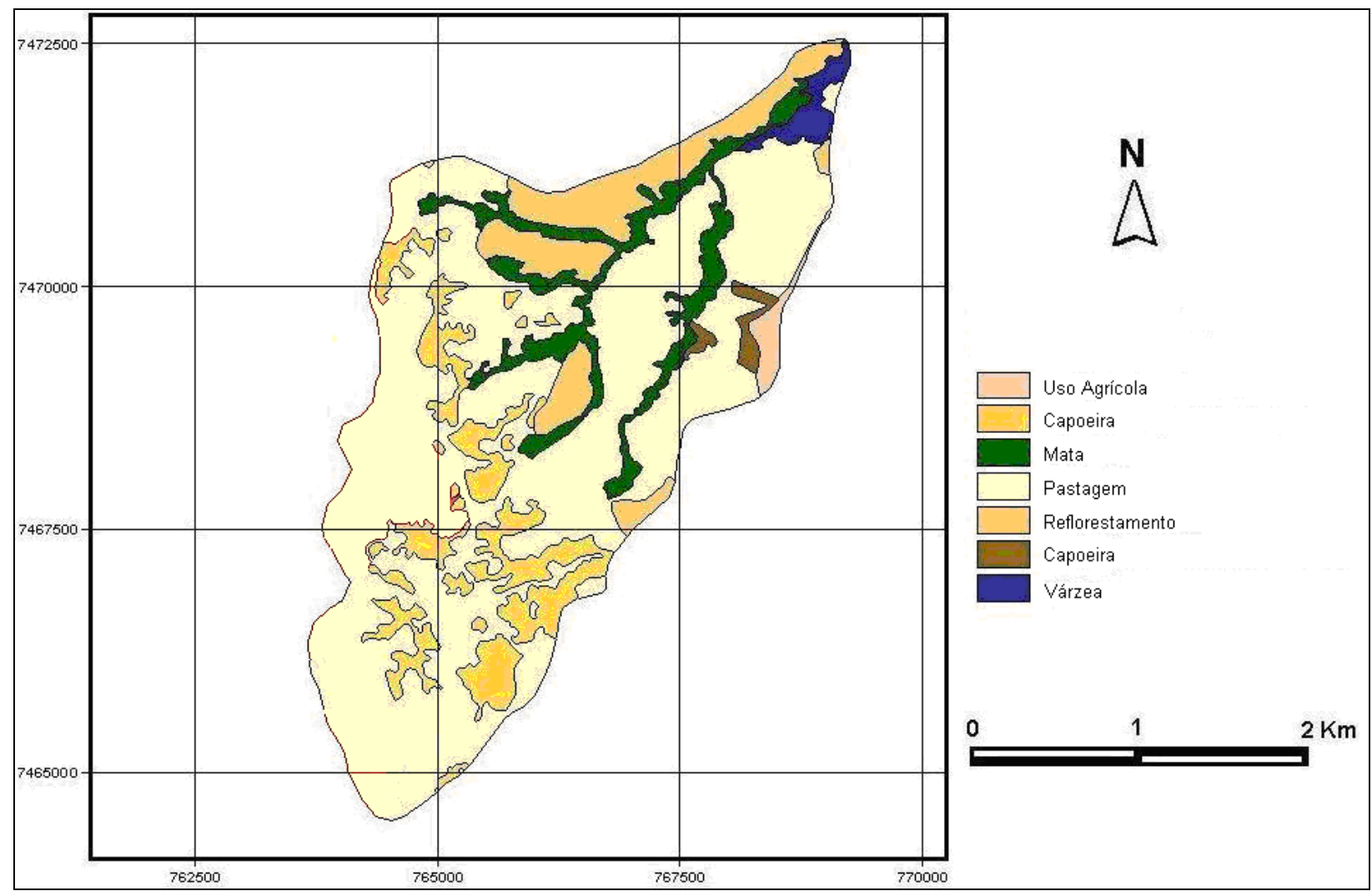

Figura 2. Ocupação do solo da microbacia do Ribeirão Descalvado - Botucatu, SP, obtida em imagens de satélite de 2006

Dentre as classes que tiveram suas áreas reduzidas no período, as capoeiras decresceram em 44,3\%, ou seja, passaram de 807,84ha (39,39\%), em 1962, para 449,97ha (21,94\%), em 2006. Essas ocupações do solo, geralmente ocupam as partes os relevos ondulados, provavelmente, porque as condições para a atividade agrícola nessas áreas são menos favoráveis, refletindo dessa maneira a predominância de solos com baixa fertilidade.

As matas, nas últimas décadas, vêm decrescendo lentamente, com ligeira estabilização na quantidade de área, apesar da sua qualidade diminuir com a decadência das essências florestais nobres e depauperação da fauna, conforme Gonçalves (1990). Esse quadro foi diferente na área, onde essa classe de uso da terra sofreu um ligeiro aumento no período de $64,75 \%$, provavelmente devido a regeneração de algumas espécies, em virtude de estarem situadas em relevo com 
topografia mais acentuada, onde as condições para a mecanização é praticamente impossível e o acesso é inacessível (Campos, 1998).

O uso agrícola e as pastagens vem representando mais de $50 \%$ da área da microbacia $(57,47 \%)$, ou seja, cobrem $1178,88 \mathrm{ha}$, mostrando com isso a predominância de solos de baixa fertilidade e da predominância da agropecuária regional (Campos, 1993).

A microbacia do Ribeirão Descalvado vem sendo conservada ambientalmente ao longo dos anos, pois as matas, de grande importância em termos de preservação ambiental, representaram mais de 30\% da área. Estas são formadas por matas ciliares, zonas de cerrado e de florestas propriamente ditas. De acordo com o Código Florestal, a reserva mínima de florestas deve ser de $20 \%$ de área de cada propriedade com cobertura arbórea.

\section{Conclusões}

As fotografias aéreas pancromáticas e as imagens de satélite permitiram o mapeamento do uso da terra de maneira confiável, que servirão de dados para futuros planejamentos regionais. Permitiram verificar também que a microbacia está sendo conservada ambientalmente, pois não há deficiência de florestamento, visto que se apresenta coberta com $30 \%$ de matas ciliares, cerrado e de florestas, sendo que o mínimo exigido pelo Código Florestal Brasileiro vigente é de $20 \%$. O alto índice de ocupação do solo por pastagem na bacia $(53,74 \%)$, reflete a predominância da pecuária regional.

\section{Referências}

Borgonovi, M.; Chiarini, J.V. Cobertura vegetal do Estado de São Paulo. I - Levantamento por fotointerpretação de áreas cobertas com cerrado, cerradão e campos em 1962. Bragantia, Campinas, v.24, n.12, p.159-72, 1965.

Campos, S. Fotointerpretação da ocupação do solo e suas influências sobre a rede de drenagem da bacia do rio Capivara - Botucatu (SP), no período de 1962 a 1977. 1993, 164p. Tese (Doutorado em Energia na Agricultura) - Universidade Estadual Paulista, Botucatu, 1993.

Campos, S., Cardoso, L.G., Barros, Z.X., Araújo Júnior, A.A., Ribeiro, F.L., Castro, T.M.R.. Evolução do uso da terra na bacia do rio Lavapés, Botucatu, SP, por um período de 27 anos. Engenharia Agrícola e Ambiental, v.2, n.1, p.1-117, 1998.

Coelho, A.G. de S. Obtenção de dados quantitativos de fotografias aéreas verticais. Aerofotogrametria, São Paulo, 1972, v.8, p.1-23.

Gonçalves, J.S. (Coord.) Anuário de informações estatísticas da agricultura. São Paulo: Secretaria da Agricultura e Abastecimento, Instituto de Economia Agrícola, 1990. 11p.

Morais, S.M.J. Diagnósticos quantitativos mínimos de ambiência para o manejo integrado da Sub-bacia do Arroio Cadena, Município de Santa Maria - RS. 1997, 135p. Dissertação (Mestrado em Engenharia Florestal) - Universidade Federal de Santa Maria, Santa Maria, 1997.

Rocha, J.S. M. Manual de manejo integrado de bacias hidrográficas. Santa Maria: Oficina de Textos, 1991. $181 \mathrm{p}$.

Rodrigues, A. C. M. Mapeamento Multitemporal do uso e cobertura do solo do município de São SebastiãoSP, utilizando técnicas de segmentação e classificação de imagens TM-Landsat e HRV-SPOT. São José dos Campos: INPE, 94p. 2000. (INPE - 7510 - PUD/39)

Vettorazzi, C.A. Sensoriamento remoto orbital. Piracicaba: USP, 1992. 134p. (Didática, 2). 